Journal of Applied Veterinary Sciences, 5 (3): 92 - 102 (2020).

ISSN: Online: 2090-3308, Print: 1687-4072

Journal homepage : https://javs.journals.ekb.eg

\title{
Immuno-Potentiator Effect of Rapeseed or Soybean Oil with Foot and Mouth Disease Vaccine in Calves
}

\author{
Elsayed E. I*.; Mossad W.G ; Ismail A.H. and Shabana Walaa \\ Department of Foot and Mouth Disease, Veterinary Serum and Vaccine Research Institute (VSVRI), Agriculture \\ Research Center, Abassia, Cairo, Egypt. \\ *Corresponding Author, Ehab EL-Sayed Ibrahim, E-mail: ehabelsayed@ hotmail.com
}

\begin{abstract}
One of the effective recommendation for control of Foot and Mouth disease virus is the proper vaccination by a highly potent vaccine. Such a vaccine should be specific to the circulated field serotype of foot and mouth disease virus inducing rapid, highly protective immunity with a long duration. This research is concerned with using plant extracted oil adjuvants prepared from rapeseed oil mixed with or without Ginseng extracts and from Soybean oil as well with or without Ginseng extracts. Some humoral and cellular immune responses were compared using the different plant-extracted oils and the mineral-based adjuvant called Montanide oil ISA 206 after one dose vaccination of the prepared vaccines at different interval times post vaccinations. Lymphocyte blastogenesis, Interleukin-6, and Interleukin-12 showed higher expression in calves vaccinated by FMDV serotypes (O pan Asia, A Iran O5, and SAT2 / EGY/2012) with plant extract oil containing Ginseng extract comparable to that of plant extracts without Ginseng and Montanide oil ISA 206 adjuvants vaccines. It was found that FMD vaccine adjuvant with ginseng either with rapeseed or Soybean showed a higher post vaccinal cellular immune response than that without ginseng or ISA 206 alone. Estimation of the humoral immune response of vaccinated calves revealed that antibody against FMD virus serotypes O pan Asia, A Iran O5 and SAT2 / EGY/2012 by SNT and ELISA assay induced by the inactivated FMD adjuvant with rapeseed oil and ginseng vaccine and the inactivated FMD adjuvant with soybean oil and ginseng vaccine were higher than those induced by inactivated FMD adjuvant with Montanide oils 206. In contrast, the obtained antibody levels by the inactivated FMD adjuvant with rapeseed oil vaccine and inactivated FMD adjuvant with soybean oil vaccine was lower than those induced by inactivated FMD adjuvant with Montanide oils 206. So, it could be concluded that the use of plant origin oil adjuvant as rapeseed and soybean oil is considered a beneficial and alternative adjuvant to the imported mineral oil as it is much cheaper and induce better post vaccinal immune responses especially when mixed with ginseng extract.
\end{abstract}

Keywords: FMD, ginseng extract, Montanide oil 206, rapeseed oil, soybean oil.

\section{J. Appl. Vet. Sci., 5(3): $92-102$.}

\section{Original Article: \\ DOI: HTTPS://DX.DOI.ORG/10.21608/ VS.2020.103394}

Received:09 June, 2020.

Accepted :12 July, 2020.

Published in:July, 2020.

This is an open access article under the term of the Creative Commons Attribution 4.0 (CC BY) International License . To view a copy of this license, visi $\underline{\text { http://creativecommons.org/licenses/by/4.0/ }}$

\section{INTRODUCTION}

Foot-and-Mouth Disease (FMD) is a highly contagious and economically important disease that affects cloven-hoofed animals causing appetite loss, high body temperature, and vesicles in the mouth, tongue, hooves, and nipples (Sobrino et al., 2001; OIE, 2017). The disease is caused by the FMD virus (FMDV), a member of the Aphthovirus genus in the Picornaviridae family. The disease's clinical severity varies with the serotypes of FMDV, infection dose, species, and individual susceptibility of the host (Cox and Barnett 2009). The disease can be transmitted via direct or indirect contact between FMDV-infected animals and susceptible animals (OIE 2017).

Foot and Mouth Disease (FMD) virus exists as seven distinct serotypes (O, A, C, Asia 1, South African Territories [SAT1, SAT2, and SAT3) as well as numerous and constantly evolving subtypes, which shows a spectrum of antigenic diversity (Cox and 
Barnett 2009; OIE, 2017). The high rate of mutations, antigenic variation, and weak cross-protection between different serotypes of FMD viruses are major challenges for controlling FMD (Nagendrakumar $\boldsymbol{e t}$ al., 2011; Park, 2013).

Vaccination remains a critical approach to control FMD in many countries. The oil-emulsified vaccine forms depots at the injection site, from which antigens are slowly released to stimulate the lymphatic system to produce a durable immune response (Li et al., 2013). Montanide ISA 206, a mineral oil-based adjuvant, is the most commonly used commercial adjuvant in China. However, the mineral oil-based adjuvant is not preferable because it is reported to cause undesirable tissue reactions, persists for long periods in animal tissues, and is potentially carcinogenic to consumers (Stone, 1993 and Yamanaka et al., 1993). Although current commercially available oil adjuvants are highly refined, searching for safer adjuvants for use in food animals remains an important topic, attracting many researchers (Roy et al., 1999; Vajdy 2011), Since the non-adjuvanted antigens do not adequately achieve some types of immune parameters (e.g., Th1 cell vs. Th2 cell, CD8+ vs. CD4+ T cells, specific antibody isotypes), the adjuvant is often formulated in vaccines to improve the efficacy of vaccination (Coffman $\boldsymbol{e t}$ al., 2010; Park, 2016).

Ginseng saponin (GS) and mineral oil synergistically activated the immune responses to the FMD vaccine in mice and pigs and the Newcastle disease vaccine in birds (Li et al., 2012). Recently edible vegetable oils extract from Soybean, corn, sunflower seeds, sesame seeds, olives, camellia seeds, and rapeseeds were used their ability to form water-inoil emulsions, and it was found that rapeseed oil (RO) could form a stable oil emulsion with a relatively low cost (Xu 2008).

In the present study, the effect of Rapeseed oil and Soybean oil rapeseed oil, Soybean and ginseng extracted oils cocktails were compared with montanide ISA 206 oils adjuvants for foot and mouth disease vaccine, in addition, to evaluate their synergistic adjuvant activities on the immune responses elicited by the FMD vaccine in a calve.

\section{MATERIALS AND METHODS \\ 1.Ethical approval}

The experiment was carried out according to the Institutional Animal Ethics Committee's protocol, and the authors had the permission of the animal owners at the private farms.

\section{FMD virus strains}

Local Foot and Mouth disease virus serotypes O pan Asia, A Iran O5 and SAT2 / EGY/2012 propagated in Baby Hamster Kidney $\left(\mathrm{BHK}_{21}\right)$ cell line monolayer was supplied by the Department of Foot and Mouth Diseases Research, Veterinary Serum and Vaccine Research Institute. The titer of the three serotypes was expressed as $\log _{10} \mathrm{TCID}_{50} / \mathrm{ml}$ as calculated by (Reed and Muench, 1938) and the complement fixation test was carried out according to(Health Protection Agency 2009). These virus serotypes were used for the preparation of trivalent inactivated vaccine as well as in serological tests.

\section{Animals \\ 3.1.Calves}

Thirty native breed calves in a private farm free from FMD antibodies screened by serum neutralization test were divided into six groups (5animals/group). Each of 5 experimental FMD trivalent vaccines adjuvanted with Rapeseed oil, rapeseed oil with ginseng oil, Soybean oil with ginseng and Montanide ISA 206 was inoculated each in a calve group and keeping one group without vaccination as a negative control group. The vaccine dose was 3 $\mathrm{ml} /$ animal inoculated subcutaneously, where each dose contains $10^{9}$ TCID $_{50}$ of each of Foot and Mouth Disease virus serotypes.

\subsection{Suckling baby mice}

Suckling Swiss baby mice, two to four days old, (Charles River Strain, USA) were used (OIE, 2017) that supplied by Laboratory Animal Department, Veterinary Serum and Vaccine Research Institute (VSVRI), Abbasia, Cairo (OIE, 2017), were used for testing of complete virus inactivation.

\section{Samples}

Heparinized blood samples were obtained from experimentally vaccinated and control non vaccinated animals at $0,3,7,14,21$ and 28 days post-vaccination, for detection of the cellular immune response of vaccinated calves to the prepared FMD vaccine formulae by Lymphocyte blastogenesis using cell proliferation kit (XTT kit), interleukine-6 and interleukine-12. In addition, serum samples were obtained from all calf groups at the time of vaccination (zero time); every week up to four weeks; every two weeks up to the $16^{\text {th }}$ week; every four weeks till the $32^{\text {nd }}$-week post-vaccination and lastly every two weeks till the end of the experiment (38 weeks postvaccination). These samples were subjected to the estimation of FMD antibodies in vaccinated animals using SNT and indirect ELISA.

\section{Cell culture}

Baby Hamster kidney cell line $\left(\mathrm{BHK}_{21}\right)$ was supplied by Veterinary Serum and Vaccine Research Institute, Abbasia, Cairo using Eagle's medium supplemented with 8-10\% bovine serum (Xuan et al., 2011)and used for the application of serum neutralization test, virus titration, and vaccine preparation. 


\section{Virus clarification and inactivation}

Each FMD virus serotype (O, A and SAT2) at the $7^{\text {th }}$ passage on BHK monolayer was treated with chloroform at a concentration of $1.5 \%$ (Volume/ Volume) as a clarification method before inactivation. Inactivation occurred using a combination of $1 \mathrm{mM}$ of Binary Ethylene amine and $0.04 \%$ formalin (BEI-FA) according to the method described by (Barteling and Cassim 2004and Ismail et al., 2013). Sodium thiosulphate $20 \%$ in a final concentration of $2 \%$ and sodium bisulphite $20 \%$ in a final concentration of $2 \%$ were added after the inactivation process to neutralize the excess of BEI and formalin residues.

\section{Used adjuvants}

- Rapeseed oil (RO) was obtained from a local food store and was manufactured according to standard GB1536 (Song et al., 2009) by the Shanghai Jiali Food Industry Co. Ltd. (Shanghai, China). One liter of RO contained 491 kilocalories of energy and $56 \mathrm{~g}$ of fat.

- Soybean oil (SO) was obtained from Sigma Aldrich (Product Number: S7381)

- Montanide ISA206 Montanide ISA 206 was obtained from Seppic, Paris, France.

- Standardized Ginseng saponin (GS) (Zhang et al., 2018) was purchased from Hongjiu Ginseng Industry Co. Ltd. (Jilin, China). Based on analysis by high-performance liquid chromatography (HPLC), GS contained Rb1 (1.4\%), Rb2 (3.0\%), Rc (2.5\%), $\operatorname{Rd}(8.0 \%), \operatorname{Re}(12.0 \%)$, and $\operatorname{Rg} 1(6.0 \%)$ and GS-R contained Rb1 (18.0\%), Rb2 (9.5\%), Rc (10.0\%), Rd (7.6\%), $\operatorname{Re}(8.7 \%)$, and $\operatorname{Rg} 1(3.5 \%)$.

\section{Formulation of the prepared experimental vaccine batches}

Five formulae of trivalent inactivated FMD vaccine were prepared using the mentioned adjuvants as follow:

- Formula (1) with Montanide ISA 206

- Formula (2) with Rapeseed oil

- Formula (3) with Rapeseed oil and ginseng

- Formula (4) with Soybean oil

- Formula (5) with Soybean oil and ginseng

The FMDV vaccine adjuvanted with ISA 206 was prepared as 50:50 for ISA 206(volume (v/v) according to (El-Sayed et al., 2015). To produce the different experimental FMDV vaccines, oil phases with 4 ug of GS were prepared by mixing GS with RO or SO containing 6\% Span-80, using dimethyl sulfoxide (DMSO) co-solvent. The aqueous phase was prepared by adding $3 \%$ Tween 80 to the FMDV antigen solution to produce an antigen solution. The oil phase was then emulsified in the aqueous phase at 1:1 ( $\mathrm{vol} / \mathrm{vol})$ with a dispersing device to produce FMD vaccines in RO containing $4 \mu \mathrm{g}$ of GS per ml. The amounts of FMDV antigen were the same in the different vaccine formulations throughout the study. The vaccines were prepared one day before immunization.

\section{Evaluation of the prepared FMD trivalent vaccine 9.1.Viscosity testing}

The vaccines' viscosities were measured according to the work of Stone (Yu and Vajdy 2011). The vaccines were removed from storage at $4{ }^{\circ} \mathrm{C}$ and allowed to equilibrate to room temperature. One milliliter of the sample was drawn into a 1-ml pipette, and then the time required for $0.4 \mathrm{ml}$ of the sample to flow out of the vertically positioned pipette was recorded.

\subsection{Sterility and safety testing}

The prepared vaccine batches were tested for their freedom of aerobic and anaerobic bacteria; fungal and mycoplasma contaminants where vaccines samples were cultured on thioglycolate broth, Sabouraud's, Nutrient agar; phenol dextrose media and mycoplasma medium. The safety of the prepared vaccines was done in baby mice (OIE, 2017).

\subsection{The Potency of the prepared vaccines}

9.3.1. Evaluation of cellular immune response 9.3.1.1.Lymphocyte blastogenesis using XTT assay

It was carried out according to (Slater et al., 1963 and EL-Naggar, 2012) through the separation of lymphocytes as described by (Lucy, 1977 and Lee, 1984) and determination of viable cell number according to (Mayer et al., 1974).

\subsubsection{Estimation of interleukin}

Estimation of interleukin in the sera of vaccinated and control calves including IL-6 levels, was carried out using calve IL-6 ELISA Kit Catalog No. EKE51028 supplied by Biomatik Company, Wilmington, Delaware, USA. Also, IL12 levels were estimated using calve IL-12 ELISA Kit Catalog No. EKE51028 supplied by Biomatik Company, Wilmington, Delaware,

\subsubsection{Evaluation of the humoral immune response}

Serum samples collected from the vaccinated calves were tested for monitoring of the exhibited FMD antibody titers against the three serotypes by serum neutralization test (SNT) using the technique described by (Ferreira, 1976) and indirect enzymelinked immune sorbent assay (ELISA) according to (Voller et al., 1976).

\section{Statistical analysis}

Data were analyzed using analysis of variance (ANOVA) in the SPSS-12 statistical software package for P.C.S. Multiple comparisons of means were made using Duncan's multiple range tests at $\mathrm{P}<0.05 \%$. 


\section{RESULTS}

Table 1: Mean delta optical density of lymphocyte blastogenesis assay in calves vaccinated with the prepared vaccine formulae

\begin{tabular}{|ccccccc|}
\hline \multirow{2}{*}{ Used Vaccine formula } & \multicolumn{5}{c|}{ Delta optical density of lymphocyte blastogenesis } \\
\cline { 2 - 7 } & $1^{\text {st }} \mathrm{DPV}^{*}$ & $3^{\text {th }} \mathrm{DPV}$ & $7^{\text {th }} \mathrm{DPV}$ & $14^{\text {th }} \mathrm{DPV}$ & $21^{\text {st }} \mathrm{DPV}$ & $28^{\text {th }} \mathrm{DPV}$ \\
\hline Formula (1) & 0.32 & 0.45 & 0.67 & 0.95 & 0.81 & 0.76 \\
\hline Formula (2) & 0.31 & 0.42 & 0.64 & 0.90 & 0.79 & 0.72 \\
\hline Formula (3) & 0.41 & 0.82 & 1.15 & 1.10 & 0.97 & 0.80 \\
\hline Formula (4) & 0.25 & 0.31 & 0.48 & 0.74 & 0.51 & 0.40 \\
\hline Formula (5) & 0.35 & 0.70 & 1.02 & 0.95 & 0.81 & 0.67 \\
\hline Control & 0.10 & 0.12 & 0.13 & 0.12 & 0.13 & 0.10 \\
\hline
\end{tabular}

Table 2: Interleukin-6 immune response expressed as mean delta optical density of calves vaccinated with the prepared vaccine formulae

\begin{tabular}{|ccccccc|}
\hline \multirow{2}{*}{ Used Vaccine formula } & \multicolumn{7}{c|}{ IL-6 $(\mathrm{ng} / \mathrm{ml})$ at DPV } \\
\cline { 2 - 7 } & $1^{\text {st }} \mathrm{DPV}^{*}$ & $3^{\text {th }} \mathrm{DPV}$ & $7^{\text {th }} \mathrm{DPV}$ & $14^{\text {th }} \mathrm{DPV}$ & $21^{\text {st }} \mathrm{DPV}$ & $28^{\text {th }} \mathrm{DPV}$ \\
\hline Formula (1) & 0.89 & 1.44 & 2.11 & 3.78 & 3.62 & 3.17 \\
\hline Formula (2) & 0.85 & 1.40 & 2.01 & 3.71 & 3.57 & 3.02 \\
\hline Formula (3) & 1.43 & 2.51 & 4.78 & 3.97 & 3.81 & 3.43 \\
\hline Formula (4) & 0.72 & 1.31 & 1.94 & 3.67 & 3.47 & 2.94 \\
\hline Formula (5) & 1.30 & 2.30 & 4.44 & 3.83 & 3.69 & 3.20 \\
\hline Control & 0.40 & 0.35 & 0.32 & 0.3 & 0.39 & 0.4 \\
\hline
\end{tabular}

Table 3: Interleukin-12 immune response expressed as mean delta optical density of calves vaccinated with the prepared vaccine formulae

\begin{tabular}{|ccccccc|}
\hline $\begin{array}{c}\text { Used Vaccine } \\
\text { formula }\end{array}$ & \multicolumn{5}{c|}{$\mathrm{IL}-12(\mathrm{ng} / \mathrm{ml})$ at DPV } \\
\cline { 2 - 7 } & $1^{\text {st }} \mathrm{DPV} *$ & $3^{\text {th }} \mathrm{DPV}$ & $7^{\text {th }} \mathrm{DPV}$ & $14^{\text {th }} \mathrm{DPV}$ & $21^{\text {st }} \mathrm{DPV}$ & $28^{\text {th }} \mathrm{DPV}$ \\
\hline Formula (1) & 4.4 & 4.61 & 5.15 & 6.2 & 5.3 & 4.9 \\
\hline Formula (2) & 4.3 & 4.56 & 5.1 & 6.3 & 5.2 & 4.8 \\
\hline Formula (3) & 4.6 & 5.6 & 7.5 & 5.8 & 5.5 & 5.3 \\
\hline Formula (4) & 4.2 & 4.4 & 5 & 6.5 & 5 & 4.6 \\
\hline Formula (5) & 4.5 & 5.8 & 6.8 & 6 & 5.4 & 5 \\
\hline Control & 4.1 & 4.3 & 4.1 & 4.2 & 4.3 & 4.1 \\
\hline
\end{tabular}

*DPV: day post vaccination

Formula (1) Trivalent FMD adjuvanted with Montanide ISA206 Formula (2) Trivalent FMD adjuvanted with Rapsead oil Formula (3) Trivalent FMD adjuvanted with Rapsead oil with Ginseng Formula (4) Trivalent FMD djuvanted with Soybean oil Formula (5) Trivalent FMD adjuvanted with Soybean oil with Ginseng 
Table 4: Mean FMD type-O serum neutralizing antibody titers expressed in $\log _{10}$ in different vaccinated calve's groups

\begin{tabular}{|ccccccccccccccccccc|}
\hline $\begin{array}{c}\text { Used } \\
\text { Vaccine } \\
\text { formula }\end{array}$ & $0 \mathrm{dPV} *$ & $1 \mathrm{~W}$ & $2 \mathrm{~W}$ & $3 \mathrm{~W}$ & $4 \mathrm{~W}$ & $6 \mathrm{~W}$ & $8 \mathrm{~W}$ & $10 \mathrm{~W}$ & $12 \mathrm{~W}$ & $14 \mathrm{~W}$ & $16 \mathrm{~W}$ & $20 \mathrm{~W}$ & $24 \mathrm{~W}$ & $28 \mathrm{~W}$ & $32 \mathrm{~W}$ & $34 \mathrm{~W}$ & $36 \mathrm{~W}$ \\
\hline Formula (1) & 0.45 & 1.45 & 1.68 & 1.71 & 2.24 & 2.51 & 2.82 & 3.11 & 2.84 & 2.72 & 2.61 & 2.32 & 2.12 & 1.84 & 1.72 & 1.47 & 1.25 \\
\hline Formula (2) & 0.3 & 1.35 & 1.45 & 1.65 & 2.13 & 2.45 & 2.7 & 3 & 2.77 & 2.65 & 2.57 & 2.26 & 2.05 & 1.65 & 1.53 & 1.35 & 1.05 \\
\hline Formula (3) & 0.32 & 1.52 & 1.71 & 1.99 & 2.34 & 2.68 & 3.35 & 3.22 & 3.05 & 2.87 & 2.79 & 2.57 & 2.4 & 2.09 & 1.7 & 1.6 & 1.24 \\
\hline Formula (4) & 0.29 & 1.23 & 1.4 & 1.51 & 1.9 & 2.18 & 2.48 & 2.82 & 2.6 & 2.48 & 2.38 & 2.04 & 1.84 & 1.71 & 1.57 & 1.15 & 0.71 \\
\hline Formula (5) & 0.3 & 1.5 & 1.63 & 1.86 & 2.14 & 2.42 & 3.01 & 2.95 & 2.8 & 2.67 & 2.53 & 2.32 & 2.16 & 1.95 & 1.81 & 1.55 & 1.17 \\
\hline & 0.3 & 0.3 & 0.4 & 0.3 & 0.4 & 0.4 & 0.4 & 0.3 & 0.3 & 0.3 & 0.3 & 0.3 & 0.3 & 0.3 & 0.3 & 0.3 & 0.3 \\
\hline
\end{tabular}

*WPV: week post vaccination

Table 5: Mean FMD type-O ELISA titer in different vaccinated calve's groups

\begin{tabular}{|c|c|c|c|c|c|c|c|c|c|c|c|c|c|c|c|c|c|}
\hline \multirow{2}{*}{$\begin{array}{c}\text { Used Vaccine } \\
\text { formula }\end{array}$} & \multicolumn{17}{|c|}{ FMD type-O ELISA antibody titer /WPV* } \\
\hline & 0WPV* & $1 \mathrm{~W}$ & $2 \mathrm{~W}$ & $3 \mathrm{~W}$ & $4 \mathrm{~W}$ & $6 \mathrm{~W}$ & $8 \mathrm{~W}$ & $10 \mathrm{~W}$ & $12 \mathrm{~W}$ & $14 \mathrm{~W}$ & $16 \mathrm{~W}$ & $20 \mathrm{~W}$ & $24 \mathrm{~W}$ & $28 \mathrm{~W}$ & $32 \mathrm{~W}$ & $34 \mathrm{~W}$ & $36 \mathrm{~W}$ \\
\hline Formula (1) & 0.75 & 1.75 & 1.98 & 2.01 & 2.54 & 2.81 & 3.12 & 3.41 & 3.14 & 3.02 & 2.91 & 2.62 & 2.42 & 2.14 & 2.02 & 1.77 & 1.55 \\
\hline Formula (2) & 0.6 & 1.65 & 1.75 & 1.95 & 2.43 & 2.75 & 3 & 3.3 & 3.07 & 2.95 & 2.87 & 2.56 & 2.35 & 1.95 & 1.83 & 1.65 & 1.35 \\
\hline Formula (3) & 0.62 & 1.82 & 2.01 & 2.29 & 2.64 & 2.98 & 3.65 & 3.52 & 3.35 & 3.17 & 3.09 & 2.87 & 2.7 & 2.39 & 2 & 1.9 & 1.54 \\
\hline Formula (4) & 0.59 & 1.53 & 1.7 & 1.81 & 2.2 & 2.48 & 2.78 & 3.12 & 2.9 & 2.78 & 2.68 & 2.34 & 2.14 & 2.01 & 1.87 & 1.45 & 1.01 \\
\hline Formula (5) & 0.6 & 1.8 & 1.93 & 2.16 & 2.44 & 2.72 & 3.31 & 3.25 & 3.1 & 2.97 & 2.83 & 2.62 & 2.46 & 2.25 & 2.11 & 1.85 & 1.47 \\
\hline Control & 0.6 & 0.6 & 0.7 & 0.6 & 0.7 & 0.7 & 0.7 & 0.6 & 0.6 & 0.6 & 0.6 & 0.6 & 0.6 & 0.6 & 0.6 & 0.6 & 0.6 \\
\hline
\end{tabular}

Table 6: Mean FMD type-A serum neutralizing antibody titers expressed in $\log _{10}$ in different vaccinated calve's groups

\begin{tabular}{|cccccccccccccccccc|}
\hline $\begin{array}{c}\text { Used } \\
\text { Vaccine } \\
\text { formula }\end{array}$ & $0 \mathrm{DPV}$ & $1 \mathrm{~W}$ & $2 \mathrm{~W}$ & $3 \mathrm{~W}$ & $4 \mathrm{~W}$ & $6 \mathrm{~W}$ & $8 \mathrm{~W}$ & $10 \mathrm{~W}$ & $12 \mathrm{~W}$ & $14 \mathrm{~W}$ & $16 \mathrm{~W}$ & $20 \mathrm{~W}$ & $24 \mathrm{~W}$ & $28 \mathrm{~W}$ & $32 \mathrm{~W}$ & $34 \mathrm{~W}$ & $46 \mathrm{~W}$ \\
\hline Formula (1) & 0.3 & 1.3 & 1.6 & 1.65 & 2.14 & 2.45 & 2.7 & 3 & 2.7 & 2.64 & 2.5 & 2.1 & 2 & 1.7 & 1.6 & 1.35 & 1.1 \\
\hline Formula (2) & 0.3 & 1.3 & 1.4 & 1.6 & 2.05 & 2.32 & 2.55 & 2.9 & 2.6 & 2.5 & 2.4 & 2 & 1.91 & 1.65 & 1.5 & 1.2 & 0.9 \\
\hline Formula (3) & 0.3 & 1.5 & 1.6 & 1.8 & 2.1 & 2.5 & 3.2 & 3 & 2.9 & 2.7 & 2.6 & 2.4 & 2.27 & 1.95 & 1.8 & 1.55 & 1.2 \\
\hline Formula (4) & 0.25 & 1.01 & 1.2 & 1.5 & 1.7 & 2 & 2.3 & 2.5 & 2.4 & 2.3 & 2.1 & 1.95 & 1.7 & 1.6 & 1.5 & 1.01 & 0.8 \\
\hline Formula (5) & 0.3 & 1.45 & 1.5 & 1.7 & 2.01 & 2.27 & 2.8 & 2.6 & 2.4 & 2.3 & 2.1 & 2.1 & 2 & 1.8 & 1.65 & 1.5 & 1.01 \\
\hline Control & 0.3 & 0.3 & 0.4 & 0.3 & 0.4 & 0.4 & 0.4 & 0.3 & 0.3 & 0.3 & 0.3 & 0.3 & 0.3 & 0.3 & 0.3 & 0.3 & 0.3 \\
\hline
\end{tabular}


Elsayed E. I et al.....

Table 7: Mean FMD type-A ELISA antibody titer in different vaccinated calve's groups

\begin{tabular}{|cccccccccccccccccc|c|}
\hline $\begin{array}{c}\text { Used } \\
\text { Vaccine } \\
\text { formula }\end{array}$ & $0 \mathrm{WPV}^{*}$ & $1 \mathrm{~W}$ & $2 \mathrm{~W}$ & $3 \mathrm{~W}$ & $4 \mathrm{~W}$ & $6 \mathrm{~W}$ & $8 \mathrm{~W}$ & $10 \mathrm{~W}$ & $12 \mathrm{~W}$ & $14 \mathrm{~W}$ & $16 \mathrm{~W}$ & $20 \mathrm{~W}$ & $24 \mathrm{~W}$ & $28 \mathrm{~W}$ & $32 \mathrm{~W}$ & $34 \mathrm{~W}$ & $36 \mathrm{~W}$ \\
\hline $\begin{array}{c}\text { Formula } \\
(1)\end{array}$ & 0.6 & 1.6 & 1.9 & 1.95 & 2.44 & 2.75 & 3 & 3.3 & 3 & 2.94 & 2.8 & 2.4 & 2.3 & 2 & 1.9 & 1.65 & 1.4 \\
\hline $\begin{array}{c}\text { Formula } \\
(2)\end{array}$ & 0.6 & 1.6 & 1.7 & 1.9 & 2.35 & 2.62 & 2.85 & 3.2 & 2.9 & 2.8 & 2.7 & 2.3 & 2.21 & 1.95 & 1.8 & 1.5 & 1.2 \\
\hline $\begin{array}{c}\text { Formula } \\
(3)\end{array}$ & 0.6 & 1.8 & 1.9 & 2.1 & 2.4 & 2.8 & 3.5 & 3.3 & 3.2 & 3 & 2.9 & 2.7 & 2.57 & 2.25 & 2.1 & 1.85 & 1.5 \\
\hline $\begin{array}{c}\text { Formula } \\
(4)\end{array}$ & 0.55 & 1.31 & 1.5 & 1.8 & 2 & 2.3 & 2.6 & 2.8 & 2.7 & 2.6 & 2.4 & 2.25 & 2 & 1.9 & 1.8 & 1.31 & 1.1 \\
\hline $\begin{array}{c}\text { Formula } \\
(5)\end{array}$ & 0.6 & 1.75 & 1.8 & 2 & 2.31 & 2.57 & 3.1 & 2.9 & 2.7 & 2.6 & 2.4 & 2.4 & 2.3 & 2.1 & 1.95 & 1.8 & 1.31 \\
\hline Control & 0.45 & 0.45 & 0.7 & 0.6 & 0.7 & 0.7 & 0.6 & 0.6 & 0.6 & 0.6 & 0.45 & 0.45 & 0.45 & 0.45 & 0.3 & 0.3 & 0.3 \\
\hline
\end{tabular}

Table 8: Mean FMD type-SAT2 serum neutralizing antibody titers expressed in $\log _{10}$ in different vaccinated calve's groups

\begin{tabular}{|c|c|c|c|c|c|c|c|c|c|c|c|c|c|c|c|c|c|}
\hline \multirow{2}{*}{$\begin{array}{c}\text { Used } \\
\text { Vaccine } \\
\text { formula }\end{array}$} & \multicolumn{17}{|c|}{ FMD type-SAT2 serum neutralizing antibody titers /WPV* } \\
\hline & OWPV* & $1 \mathrm{~W}$ & $2 \mathrm{~W}$ & $3 \mathrm{~W}$ & $4 \mathrm{~W}$ & $6 \mathrm{~W}$ & $8 \mathrm{~W}$ & $10 \mathrm{~W}$ & $12 \mathrm{~W}$ & $14 \mathrm{~W}$ & $16 \mathrm{~W}$ & 20W & $24 \mathrm{~W}$ & $28 \mathrm{~W}$ & $32 \mathrm{~W}$ & $34 \mathrm{~W}$ & $36 \mathrm{~W}$ \\
\hline $\begin{array}{c}\text { Formula } \\
\text { (1) }\end{array}$ & 0.45 & 1.25 & 1.5 & 1.55 & 2.01 & 2.3 & 2.55 & 2.9 & 2.64 & 2.5 & 2.35 & 2 & 1.9 & 1.6 & 1.5 & 1.2 & 0.9 \\
\hline $\begin{array}{l}\text { Formula } \\
(2)\end{array}$ & 0.3 & 1.1 & 1.3 & 1.5 & 2 & 2.18 & 2.4 & 2.75 & 2.45 & 2.35 & 2.21 & 1.95 & 1.8 & 1.55 & 1.5 & 1.1 & 0.65 \\
\hline $\begin{array}{c}\text { Formula } \\
\text { (3) }\end{array}$ & 0.45 & 1.45 & 1.5 & 1.6 & 2 & 2.3 & 3 & 2.9 & 2.8 & 2.5 & 2.41 & 2.21 & 2.14 & 1.8 & 1.55 & 1.5 & 1.02 \\
\hline $\begin{array}{c}\text { Formula } \\
\text { (4) }\end{array}$ & 0.3 & 0.9 & 1.05 & 1.3 & 1.5 & 1.8 & 2 & 2.2 & 2 & 1.9 & 1.8 & 1.7 & 1.54 & 1.5 & 1.47 & 0.9 & 0.4 \\
\hline $\begin{array}{c}\text { Formula } \\
\text { (5) }\end{array}$ & 0.3 & 1.5 & 1.6 & 1.7 & 2 & 2.1 & 2.6 & 2.5 & 2.3 & 2.1 & 1.95 & 1.95 & 1.8 & 1.65 & 1.5 & 1.5 & 0.9 \\
\hline Control & 0.3 & 0.3 & 0.4 & 0.3 & 0.4 & 0.4 & 0.4 & 0.3 & 0.3 & 0.3 & 0.3 & 0.3 & 0.3 & 0.3 & 0.3 & 0.3 & 0.3 \\
\hline
\end{tabular}

Table 9: Mean FMD type-SAT2 ELISA antibody titer in different vaccinated calve's groups

\begin{tabular}{|cccccccccccccccccccc|}
\hline $\begin{array}{c}\text { Used } \\
\text { Vaccine } \\
\text { formula }\end{array}$ & $0 \mathrm{WPV}^{*}$ & $1 \mathrm{~W}$ & $2 \mathrm{~W}$ & $3 \mathrm{~W}$ & $4 \mathrm{~W}$ & $6 \mathrm{~W}$ & $8 \mathrm{~W}$ & $10 \mathrm{~W}$ & $12 \mathrm{~W}$ & $14 \mathrm{~W}$ & $16 \mathrm{~W}$ & $20 \mathrm{~W}$ & $24 \mathrm{~W}$ & $28 \mathrm{~W}$ & $32 \mathrm{~W}$ & $34 \mathrm{~W}$ & $36 \mathrm{~W}$ \\
\hline $\begin{array}{c}\text { Formula } \\
(1)\end{array}$ & 0.75 & 1.55 & 1.8 & 1.85 & 2.31 & 2.6 & 2.85 & 3.2 & 2.94 & 2.8 & 2.65 & 2.3 & 2.2 & 1.9 & 1.8 & 1.5 & 1.2 \\
\hline $\begin{array}{c}\text { Formula } \\
(2)\end{array}$ & 0.6 & 1.4 & 1.6 & 1.8 & 2.3 & 2.48 & 2.7 & 3.05 & 2.75 & 2.65 & 2.51 & 2.25 & 2.1 & 1.85 & 1.8 & 1.4 & 0.95 \\
\hline $\begin{array}{c}\text { Formula } \\
(3)\end{array}$ & 0.75 & 1.75 & 1.8 & 1.9 & 2.3 & 2.6 & 3.3 & 3.2 & 3.1 & 2.8 & 2.71 & 2.51 & 2.44 & 2.1 & 1.85 & 1.8 & 1.32 \\
\hline $\begin{array}{c}\text { Formula } \\
(4)\end{array}$ & 0.6 & 1.2 & 1.35 & 1.6 & 1.8 & 2.1 & 2.3 & 2.5 & 2.3 & 2.2 & 2.1 & 2 & 1.84 & 1.8 & 1.77 & 1.2 & 0.7 \\
\hline $\begin{array}{c}\text { Formula } \\
(5)\end{array}$ & 0.6 & 1.8 & 1.9 & 2 & 2.3 & 2.4 & 2.9 & 2.8 & 2.6 & 2.4 & 2.25 & 2.25 & 2.1 & 1.95 & 1.8 & 1.8 & 1.2 \\
\hline Control & 0.45 & 0.45 & 0.7 & 0.6 & 0.7 & 0.7 & 0.6 & 0.6 & 0.6 & 0.6 & 0.45 & 0.45 & 0.45 & 0.45 & 0.3 & 0.3 & 0.3 \\
\hline
\end{tabular}




\section{DISCUSSION}

The beneficial effects of the formulation of adjuvants in vaccines include induction of higher levels of immunity, reduction of the required antigen dose, increasing the speed of attainment of protective immunity as well as reducing the number of immunizations and modulating the phenotype of $\mathrm{T}$ cell responses. In this respect and through the present work, we try to provide the best natural oil adjuvant to the trivalent inactivated FMD vaccine that could induce high immunity with a long duration in vaccinated calves. So, we prepared four trivalent FMD vaccine formulae using Rapeseed oil, Rapeseed oil with Ginseng, Soybean oil and Soybean oil with ginseng as natural oil adjuvants in addition to a fifth formula using Montanide ISA 206 subjected to comparative evaluation to determine the best adjuvant which confirms our suggested purpose.

Specific antibody responses are important in defense against FMD (Meloen et al., 1979; McCullough et al., 1986.; McCullough et al., 1988 and McCullough et al., 1992). Protection against FMDV infection is considered to be closely related to serum antibody levels (Xie $\boldsymbol{e}$ t al., 2005). High FMDV specific IgG isotype levels were associated with the protection of swine challenged with FMD (Mayr et al., 2001). The rapeseed oil combined with ginseng rapeseed oil promoted a significantly greater serum IgG response induced by FMD vaccine than did rapeseed oil or ginseng alone (Zhang et al., 2014).

Regarding the cellular immune response of calves to different FMD vaccine formulae through estimation of the lymphocyte blastogenesis, in addition to IL-6 and IL-12 levels as the efficient induction of early protection against infection with FMDV relies on the rapid assimilation of appropriate innate immune defense, probably leading to the enhanced induction of specific immune responses (Barnett et al., 2002). The results of estimation of the lymphocyte blastogenesis , IL-6 and IL-12 as shown in Table no. 1, 2 and 3 come in parallel to each other's as the cellular immune response of calves to the five formulations showed an increase in the mean delta optical density of lymphocyte blastogenesis assay, IL-6 and IL-12 at day 1 while the peak value of the lymphocyte blastogenesis assay, IL-6 and IL-12 varies from one formula to another as in calves vaccinated with inactivated FMD ISA 206 oil vaccine (Formula-1), calves vaccinated with inactivated FMD adjuvant with rapeseed oil vaccine (Formula-2) and calves vaccinated with inactivated FMD adjuvant with soybeans oil vaccine (Formula-4), the mean delta optical density of lymphocyte blastogenesis assay, IL-6 and IL-12 showed its maximum value at the $14^{\text {th }}$ DPV then declined while the inactivated FMD adjuvant with rapeseed oil and ginseng vaccine (Formula-3) and the inactivated FMD adjuvant with soybean oil and ginseng vaccine (Formula-5), the mean delta optical density of lymphocyte blastogenesis assay, IL-6 and IL-12 showed its maximum value at the $7^{\text {th }}$ DPV then declined . Compared with the control calves remain to mean delta optical density of lymphocyte blastogenesis assay, IL-6 and IL-12 remain in an average constant value all over the time of estimation.

From the above results and the statistical analysis of cellular immunity, it is clear that the FMD vaccine adjuvant with ginseng either with rapeseed or Soybean induced a higher post vaccinal cellular immune response than that induced without mixing with ginseng or ISA 206 alone.

These results came in agreement with (Song $\boldsymbol{e t}$ al., 2009; Li et al., 2012 and Zhang et al., 2014) who reported that Rapeseed oil in combination with ginseng significantly enhanced serum $\operatorname{IgG}$ and isotype concentrations, gamma interferon (IFN- $\gamma$ ) and interleukin 5 (IL-5) levels, splenocyte proliferative responses to stimulations with concanavalin A (ConA), lipopolysaccharide (LPS), and FMDV antigen, and the numbers of IgG-secreting plasma cells in the bone marrow, suggesting that Rapeseed oil with ginseng enhanced both Th1 and Th2 immune responses, Also our results come in agreement in some points with those of (Knudsen et al., 1979; Mercedes et al., 1996; Elwatany et al., 1999; Sonia et al., 2010; Fakhry et al., 2012 and Mossad et al., 2014) who mentioned that the Delta optical density of lymphocyte blastogenesis assay and interleukin6, 12 at day 0, 3, 7, 14, 21 and 28 days post vaccination (DPV) showed a significant difference between vaccinated and control groups started at $3^{\text {rd }}$ DPV and increased gradually till $21^{\text {st }} \mathrm{DPV}$ using trivalent FMD Montanide inactivated vaccine.

Evaluation of the humoral immune response against FMDV serotype (O) in vaccinated calves with different prepared oil adjuvant vaccine formulae using SNT and ELISA data (Tables 4 and 5) showed differences in the onset, intensity and duration of the FMDV serotype $(\mathrm{O})$ antibodies. Concerning the onset of protective antibody titer either estimated by SNT or ELISA, it is clear that calves vaccinated with inactivated FMDV adjuvanted with rapeseed oil and ginseng vaccine (Formula-3) and calves vaccinated with inactivated FMDV adjuvanted with soybean oil and ginseng vaccine (Formula-5) showed an earlier immune response in the $1^{\text {st }}$ WPV while the calves vaccinated with inactivated FMDV adjuvanted with Montanide ISA 206 oil vaccine (Formula-1) showed its early immune response in the $2^{\text {nd }}$ WPV unlike the calves vaccinated with inactivated FMDV adjuvanted 
with rapeseed oil vaccine (Formula-2) and the calves vaccinated with inactivated FMDV adjuvanted with soybeans oil vaccine (Formula-4) induced its early antibody titer against FMDV serotype $(\mathrm{O})$ in the $3^{\text {rd }}$ WPV.

Concerning the peak of the protective antibody titers either estimated by SNT or ELISA against FMDV serotype (O) induced by the calves vaccinated with inactivated FMDV adjuvanted with Montanide ISA 206 oil vaccine (Formula-1), the calves vaccinated with inactivated FMDV adjuvanted with rapeseed oil vaccine (Formula-2) and calves vaccinated with inactivated FMDV adjuvanted with soybeans oil vaccine (Formula-4) appeared in the $10^{\text {th }} \mathrm{WPV}$ while the calves vaccinated with inactivated FMDV adjuvanted with rapeseed oil and ginseng vaccine (Formula-3) and calves vaccinated with inactivated FMDV adjuvanted with soybean oil and ginseng vaccine (Formula-5) induced the peak of antibody titers in the $8^{\text {th }} \mathrm{WPV}$.

Regarding the duration of the protective type (O) antibody titers either estimated by SNT or ELISA, it is clear that calves vaccinated with inactivated FMD adjuvanted with rapeseed oil and ginseng vaccine (Formula-3) and calves vaccinated with inactivated FMDV adjuvanted with soybean oil and ginseng vaccine (Formula-5) showed the longest duration of protective antibody titers against FMDV serotype (O) up to $34^{\text {th }} \mathrm{WPV}$ while the calves vaccinated with inactivated FMDV adjuvanted with Montanide ISA 206 oil vaccine (Formula-1), the calves vaccinated with inactivated FMDV adjuvanted with rapeseed oil vaccine (Formula-2) and calves vaccinated with inactivated FMDV adjuvanted with soybeans oil vaccine (Formula-4) showed protective titers against FMDV serotype (O) up to the 32nd WPV.

Regarding the FMDV serotype (A) antibody titers induced in vaccinated calves with the different prepared vaccines, formulae are determined by using SNT and ELISA as shown in tables 6 and 7 showed differences in the onset, intensity and duration of the FMD serotype (A) antibodies. Concerning the onset of protective antibody titer, it is clear that calves vaccinated with the inactivated FMDV adjuvanted with rapeseed oil and ginseng vaccine (Formula-3) showed an earlier immune response in the $1^{\text {st }}$ WPV while calves vaccinated with inactivated FMDV adjuvanted with rapeseed oil vaccine (Formula-2) and calves vaccinated with inactivated FMDV adjuvanted with soybeans oil vaccine (Formula-4) induced protective type A antibody titer in the $3^{\text {rd }}$ WPV unlike calves vaccinated with the inactivated FMDV ISA 206 oil vaccine (Formula-1) and calves vaccinated with the inactivated FMDV adjuvanted with soybean oil and ginseng vaccine (Formula-5) revealed antibody titer in the $2^{\text {nd }}$ WPV. Concerning the peak of the protective antibody titers against FMDV serotype (A) either estimated by SNT or ELISA induced by calves vaccinated with the inactivated FMDV adjuvanted with Montanide ISA 206 oil vaccine (Formula-1), calves vaccinated with inactivated FMDV adjuvanted with soybeans oil vaccine (Formula-4) and calves vaccinated with inactivated FMDV adjuvanted with rapeseed oil vaccine (Formula-2) appeared in the $10^{\text {th }}$ WPV while that induced by the calves vaccinated with the inactivated FMDV adjuvanted with rapeseed oil and ginseng vaccine (Formula-3) and calves vaccinated with the inactivated FMDV adjuvanted with soybean oil and ginseng vaccine (Formula-5) was achieved at $8^{\text {th }}$ WPV.

Regarding the duration of the protective type (A) antibody titers either estimated by SNT or ELISA, it is clear that calves vaccinated with inactivated FMD adjuvanted with rapeseed oil and ginseng vaccine (Formula-3) and calves vaccinated with inactivated FMDV adjuvanted with soybean oil and ginseng vaccine (Formula-5) showed the longest duration of protective antibody titers against FMDV serotype (A) up to $34^{\text {th }}$ WPV while the calves vaccinated with inactivated FMDV adjuvanted with Montanide ISA 206 oil vaccine (Formula-1), the calves vaccinated with inactivated FMDV adjuvanted with rapeseed oil vaccine (Formula-2) and calves vaccinated with inactivated FMDV adjuvanted with soybeans oil vaccine (Formula-4) showed protective titers against FMDV serotype (A) up to the 32nd WPV.

Results of FMD type SAT2/Egypt/2012 antibody titers induced in vaccinated calves with the prepared different oil vaccine formulae using SNT and ELISA data (Tables-8 and 9) showed differences in the onset, intensity and duration of the FMD serotype SAT2/Egypt/2012 antibodies. Concerning the onset of protective antibody titer either estimated by SNT or ELISA, it is clear that calves vaccinated with inactivated FMDV adjuvanted with soybean oil and ginseng vaccine (Formula-5) showed an earlier immune response in the $1^{\text {st }}$ WPV while the calves vaccinated with inactivated FMDV adjuvanted with Montanide ISA 206 oil vaccine (Formula-1) and calves vaccinated with inactivated FMDV adjuvanted with rapeseed oil and ginseng vaccine (Formula-3) showed its early immune response in the $2^{\text {nd }}$ WPV unlike the calves vaccinated with inactivated FMDV adjuvanted with rapeseed oil vaccine (Formula-2) induced its early antibody titer against FMDV serotype (SAT2/Egypt/2012) in the $3^{\text {rd }}$ WPV and the calves vaccinated with inactivated FMDV adjuvanted with soybeans oil vaccine (Formula-4) induced its early antibody titer against FMDV serotype 
(SAT2/Egypt/2012) in the $4^{\text {th }}$ WPV. Concerning the peak of the protective antibody titers either estimated by SNT or ELISA against FMDV serotype (SAT2/Egypt/2012) induced by the calves vaccinated with inactivated FMDV adjuvanted with Montanide ISA 206 oil vaccine (Formula-1), the calves vaccinated with inactivated FMDV adjuvanted with rapeseed oil vaccine (Formula-2) and calves vaccinated with inactivated FMDV adjuvanted with soybeans oil vaccine (Formula-4) appeared in the $10^{\text {th }}$ WPV while the calves vaccinated with inactivated FMDV adjuvanted with rapeseed oil and ginseng vaccine (Formula-3) and calves vaccinated with inactivated

FMDV adjuvanted with soybean oil and ginseng vaccine (Formula-5) induced the peak of antibody titers in the $8^{\text {th }}$ WPV. Regarding the duration of the protective type (SAT2/Egypt/2012) antibody titers either estimated by SNT or ELISA, it is clear that calves vaccinated with inactivated FMD adjuvanted with rapeseed oil and ginseng vaccine (Formula-3) and calves vaccinated with inactivated FMDV adjuvanted with soybean oil and ginseng vaccine (Formula-5) showed the longest duration of protective antibody titers against FMDV serotype (SAT2/Egypt/2012) up to $34^{\text {th }}$ WPV while the calves vaccinated with inactivated FMDV adjuvanted with Montanide ISA 206 oil vaccine (Formula-1), the calves vaccinated with inactivated FMDV adjuvanted with rapeseed oil vaccine (Formula-2) showed protective titers against FMDV serotype (SAT2/Egypt/2012) up to the 32nd WPV unlike the calves vaccinated with inactivated FMDV adjuvanted with soybeans oil vaccine (Formula-4) showed its protective titers against FMDV serotype (SAT2/Egypt/2012) up to the $28^{\text {th }}$ WPV.

From the above results and the statistical analysis of humeral antibody titers against FMDV serotypes O, A and SAT2/Egypt/2012 showed that most rapid onset of immunity and the most prolonged duration of protective titer was achieved through calves vaccinated with inactivated FMD adjuvanted with rapeseed oil and ginseng vaccine (Formula-3) and calves vaccinated with inactivated FMDV adjuvanted with soybean oil and ginseng vaccine (Formula-5) and those two formulations achieve the rapid peak level in the results of the estimation of the cellular immune response either the lymphocyte blastogenesis assay or IL-6 or IL-12 levels and that relies on the rapid assimilation of appropriate innate immune defense, probably leading to the enhanced induction of specific immune responses (Barnett $\boldsymbol{e t}$ al., 2002). It is well known that protection against FMDV infection is considered to be closely related to serum antibody levels (Xie et al., 2005).
These results came parallel to those obtained by (Zhang et al., 2014) who mentioned that no significant difference was found between rapeseed oil and the commercial adjuvant oil ISA 206 in the promotion of FMD Asialvaccine-induced immune responses; also it was found that the FMDV-specific IgG levels produced from rapeseed ginseng FMD oil vaccine were higher than those produced from rapeseed FMD oil vaccine when compared between the adjuvant activities of ginseng rapeseed oil FMD vaccine and rapeseed oil FMD vaccine. The rapeseed oil in combination with ginseng rapeseed oil promoted a significantly greater serum $\operatorname{IgG}$ response induced by FMD vaccine than did rapeseed oil or ginseng alone (Zhang et al., 2014). The present obtained FMD antibody titers of FMD could be considered of high protective levels as determined by SNT and ELISA in agreement with what recommended by (OIE, 2017) as $1.5 \log _{10}$ by SNT and $1.8 \log _{10}$ by ELISA. In this respect, it was concluded that high FMDV specific IgG isotype levels were related to the protection of swine challenged with FMD (Mayr et al., 2001).

Our results confirmed that those reported by (Xuemei et al., 2019) who approved ginsengs, exert a synergistic adjuvant effect on the immune responses to the FMD vaccine emulsified in Soybean. Soybean ginseng and ISA 206 behave differently in their adjuvant activity. When mice were immunized with the FMD vaccine emulsified in Soybean containing ginseng, significantly higher and earlier serum FMDVspecific IgG production was found than in the ISA 206 group. Although both adjuvants significantly enhanced lymphocyte proliferation response promoted the production of IL-4 and IL-6. Soybean ginseng promoted a significantly higher lymphocyte proliferative response and the $\mathrm{CD} 4+/ \mathrm{CD} 8+\mathrm{T}$ cell ratio with the production of increased IFN- $\gamma$, as compared with the ISA 206 group. (EL-Sayed et al., 2015) indicated that vaccines emulsified using Montanide ISA 201 adjuvant elicited a protective humoral immune response from the $2^{\text {nd }}$ WPV for ISA 206. It also came in parallel with (Wisniewski et al., 1972) who explained that the SNT measures those antibodies that neutralize FMD virion's infectivity. The peak of antibody titer in all groups at $10-12$ weeks postvaccination and continues with a protective level until $32^{\text {th }} \mathrm{WPV}$.

\section{CONCLUSIONS}

To achieve a rapid onset and long duration immunity against FMDV, we can use ginseng extract to rapeseed oil or Soybean oil as an adjuvant in inactivated FMDV vaccine in comparison with that adjuvanted with Montanide ISA 206 oil or with rapeseed oil or with Soybean oil. 


\section{REFERENCES}

BARNETT, P.V., COX S.J., AGGARWAL, N., GERBER, H., AND MCCULLOUGH, K.C. 2002. Further studies on the early responses of pigs following immunization with high potency foot and mouth disease vaccine. Vaccine, 19: 3197-208.

BARTELING SJ AND CASSIM NI 2004. Very fast (and safe) inactivation of FMD virus and enteroviruses by a combination of Binary ethylenimine and formaldehyde. Schudel A, Lombard M (eds): Control of infections animal disease by vaccination. Biol.Basel, Kager, Vol, 119, pp 449-455.

COFFMAN, R.L.; SHER, A. AND SEDER, R.A.2010. Vaccine Adjuvants. Putting Innate Immunity to Work. Immunity, 33, 492-503.

COX SJ AND BARNETT PV 2009. Experimental evaluation of foot-and-mouth disease vaccines for emergency use in ruminants and pigs: a review. Vet Res, 40:13-42.

EL-NAGGAR, H., 2012.Preparation of inactivated lyophilized NDV vaccine, M.V.Sc in Veterinary Science (Virology). Cairo University.

EL-SAYED E. IBRAHIM, WAEL MOSSAD GAMAL, AMR ISMAIL HASSAN, SAFY EL-DIN MAHDY, AKRAM ZAKRIA HEGAZY AND MAGDY MAHMOUD ABDEL-ATTY 2015.Comparative study on the immunopotentiator effect of ISA 201, ISA 61, ISA 50, ISA206 used in trivalent foot and mouth disease vaccine.Veterinary World, EISSN: 22310916, P.(1189-1198)

EL-WATANY, H., SHAWKY, M., RHSHDY, O.H., AND EL- KELANY, S. 1999. Relationship between cellular and humoral immunity responses in animals vaccinated with FMD vaccine. Zagazig Veterinary MedicalJournal, 27: 137-143.

FAKHRY, H.M., RIZK, S.A., ABU-ELNAGA, H.I., DEGHAIDY, W., TALAAT, A.A., AND HEGAZI, A.Z.2012. Field application of bivalent foot and mouth disease vaccine adjuvanted with Montanide ISA (25, $50,206)$ and IMS (1113-3015) as an alternative to aluminum hydroxide gel. Egypt. J. Virol., 9(1): 123136.

FERREIRA， M.E.V. 1976.Prubademicroneutralization poraestudies de anticueropos de la fibreaftosa. $13^{\text {th }}$ CentropanamericanoFiebreAftosa, (21/22): 17-24.

HEALTH PROTECTION AGENCY, 2009. Complement fixation tests. Issue No.3 Issue date 11.12.09 Issued by standards unit, Department for Evaluations, standards and Training page 1 of 23 .

ISMAIL，A.H., EL-MAHDY, S.A., MOSSAD, W.G., ABD EL-KRIM, A.S., ABOU EL-YAZID, M. AND ALI, S.M 2013. Optimization of the inactivation process of FMD virus serotype SAT-2 by binary ethyleneimine (BEI). J. Vet, Adv., 3(3): 117-124.

KNUDSEN, R.C., GROOCOCK, C.M., AND AADERSON, A.A. 1979. Immunity to foot-and-mouth disease virus in guinea pigs: clinical and immune responses. Infection and immunity 24: 787-792.

LEE, L.F., 1984. Proliferative response of chicken B and T lymphocyte to mitogen. Veterinary Medicine Journal, 15: 44-52.
LI, Y.; XIE, F.; CHEN, J.; FAN, Q.; ZHAI, L.; HU, S. 2012. Increased Humoral Immune Responses of Pigs to Foot-and-Mouth Disease Vaccine Supplemented with Ginseng Stem and Leaf Saponins. Chem. Biodivers., 9, 2225-2235.

LI, D.; ZHOU, C.; SHE, D.; LI, P.; SUN, P.; BAI, X.; CHEN, Y.; XIE, B. AND LIU, Z.2013.The comparison of the efficacy of swine FMD vaccine emulsified with oil adjuvant of ISA 201 VG or ISA 206 VG. J. Biosci. Med., 01, 22-25.

LUCY, F.L., 1977. Chicken Lymphocyte stimulation by mitogens. A microassay with whole blood cultures. Avian Disease, 22: 296-307.

MAYER, S., FALKENRODT, A., AND TONGIO, M.M., 1974. Anomalous reactivity of sera containing cold lymphocytotoxins with chronic leukemic lymphocytes. Tissue Antigens, 4: 266-270.

MAYR GA, O'DONNELL V, CHINSANGARAM J, MASON PW, AND GRUBMAN MJ. 2001. Immune responses and protection against foot-and-mouth disease virus (FMDV) challenge in swine vaccinated with adenovirus-FMDV constructs. Vaccine, 19:21522162.http://dx.doi.org/10.1016/S0264-410X(00)00384.

MCCULLOUGH KC, CROWTHER JR, BUTCHER RN, CARPENTER WC, BROCCHI E, CAPUCCI L AND DE SIMONE F. 1986. Immune protection against foot and mouth disease virus studied using virus-neutralizing and non-neutralizing concentrations of monoclonal antibodies. Immunology 58: 421-428.

MCCULLOUGH KC, PARKINSON D, AND CROWTHER JR. 1988. Opsonizationenhanced phagocytosis of foot-and-mouth disease virus. Immunology, 65:187-191.

MCCULLOUGH KC, DE SIMONE F, BROCCHI E, CAPUCCI L, CROWTHER JR AND KIHM U. 1992. The protective immune response against footand-mouth disease.J. Virol.,66:1835-1840.

MELOEN RH, ROWLANDS DJ AND BROWN F. 1979. Comparison of the antibodies elicited by the individual structural polypeptides of foot-and-mouth disease and polioviruses. J. Gen. Virol.,45:761-763. http://dx.doi.org/10 .1099/0022-1317-45-3-761.

MERCEDES G. V.,TIMOTHY D., TREVOR C., MARTIN R. AND R. MICHAEL E. P. 1996.Recognition of foot-and-mouth disease virus and its capsid protein VP1 by bovine peripheral T lymphocytes.Journal of General Virology, 77, 727-735.

MOSSAD W. GAMAL EL-DIN, EHAB EL-SAYED IBRAHIM, HIND DAOUD, AND SAMIR MOHAMED ALI 2014. The humeral and cellular immune response of Egyptian trivalent foot and mouth disease oil vaccine in sheep. Res. Opin. Anim. Vet. Sci., 4(4): 178-185.

NAGENDRA KUMAR SB, SRINIVASAN VA, MADHANMOHAN M, YUVARAJ S, PARIDA S, DINARDO A, HORSINGTON J AND PATON DJ 2011. Evaluation of cross-protection between $\mathrm{O}_{1}$ Manisa and $\mathrm{O}_{1}$ Campos in cattle vaccinated with foot-andmouth disease virus vaccine incorporating different payloads of inactivated O1Manisa antigen. Vaccine, 29:1906-1912.

OIE WORLD ORGANISATION FOR ANIMAL HEALTH 2017. Manual of diagnostic tests and 
vaccines for terrestrial animals, OIE, Paris. Available at: $\quad$ www.oie.int/en/international-standardsetting/ terrestrial-manual/access-online/ (accessed on 4 August 2018)

PARK, J.H.2013. Requirements for improved vaccines against foot-and-mouth disease epidemics. Clin. Exp. Vaccine Res. 2, 8-18.

PARK, M.-E.; LEE, S.-Y.; KIM, R.-H.; KO, M.-K.; PARK, J.-N.; LEE, K.-N.; KIM, S.-M.; CHOI, J.H.; YOU, S.-H. AND KIM, B.; 2016. Altered adjuvant of foot-and-mouth disease vaccine improves immune response and protection from virus challenge. Trials Vaccinol., 5, 97-104.

REED, L.J., AND MUENCH, H., 1938. A simple method for estimating fifty percent $(50 \%)$ endpoints. Am. J. Hyg., 27: 493-497.

ROY P, VENUGOPALAN AT AND KOTEESWARAN A. 1999. Efficacy of live adjuvantedmesogenic Newcastle disease vaccine in chickens. Vaccine, 17: 2674-2676.

SLATER, T.F., SAWYER, B., AND STRÄULI, U., 1963. Studies on the succinate-tetrazolium reductase system: III. Points of coupling of four different tetrazolium salts. Biochemical biophysical Acta, 77: 383-393.

SOBRINO F, SÁIZ M, JIMÉNEZ-CLAVERO MA, NÚÑEZ JI, ROSAS MF, BARANOWSKI E AND LEY V 2001. Foot-and-mouth disease virus: a long known virus, but a current threat. Vet Res, 32:1-30.

SONG, X.; BAO, S.; WU, L. AND HU, S. 2009. Ginseng stem-leaf saponins (GSLS) and mineral oil act synergistically to enhance the immune responses to vaccination against foot-and-mouth disease in mice. Vaccine, 27, 51-55.

SONIA,A., RIZK, HIAM, M., FAKHRY AND ABUELNAGA, H.I. 2010.Comparative study of $\mathrm{T}$ cell proliferative response in cattle vaccinated with FMD vaccine using Cell titre Aqueous one solution nonradioactive assay (MTS). Zag. Vet. J. (ISSN. 11101458) Vol. 38, No. 4 pp. 188-195.

STONE HD. 1993. Efficacy of experimental animal and vegetable oil emulsion vaccines for Newcastle disease and avian influenza. Avian Dis. 37:399-405.

VAJDY, M., 2011.Immunomodulatory properties of vitamins, flavonoids and plant oils and their potential as vaccine adjuvants and delivery systems. Expert Opin. Biol. Ther.,11:1501-1513.

VOLLER, A., BID WELL, D. AND BARTLEHA 1976. Microplate enzyme immunoassay for the immunodiagnosis of virus infection. Am. Soc. For Micro.(506-512).

WISNIEWSKI J., KOBUSIEWIECZ T., BARONOWSKI C.,AND JANKOWSKO J., 1972.Determination of the level of immunity in cattle on the basis of neutralizing antibodies after the use of Frenkel type FMD vaccine.Medycyna Wet, 28 (10):586-588.
XIE Q, LI Y, AND ZHANG M. 2005. Detection of immune response to swine fever and FMD on a pig farm in Ningxia Province. Gansu J. Anim. Husb. Vet.,35:8-10.

XU WP. 2008. Analysis and outlook of the current market of edible vegetable oil. Agric. Outlook, 3:10-13.

XUAN H., LI Y., FANG, H., AND ZHENG, C. 2011. Establishment of persistent infection with foot and mouth disease virus in BHK-21 cells. Virol. J., 8: 169.

XUEMEI CUI, YONG WANG, BABAR MAQBOOL, LIJIA YUAN, SHANSHAN HE, CENRONG ZHANG, WEI XU AND SONGHUA HU 2019. Early IgG Response to Foot and Mouth DiseaseVaccine Formulated with a Vegetable Oil Adjuvant. Vaccines, 7, 143; DOI:10.3390/vaccines7040143.

YAMANAKA M, OKABE T, NAKAI M AND GOTO N. 1993.Local pathological reactions and immune response of chickens to ISA-70 and other adjuvants containing Newcastle disease virus antigen. Avian Dis., 37:459-466.

YU, M., AND VAJDY, M., 2011.A novel retinoic acid, catechin hydrate and mustard oil-based emulsion for enhanced cytokine and antibody responses against multiple strains of HIV-1 following mucosal and systemic vaccinations. Vaccine, 29, 2429-2436.

ZHANG CENRONG, WEI XU, JIAN CHEN, RAN GUAN, SHICHENG BI, HAIBO JIN, XUEMEI CUI, FUSHAN SHI AND SONGHUA HU 2014. Soybean oil containing ginseng saponins as adjuvants promotes production of cytokines and enhances immune responses to the foot-and-mouth disease vaccine. Microbiol Immunol, 62: 187-194 DOI: 10.1111/1348-0421.12567.

ZHANG, C.; XU, W.; CHEN, J.; GUAN, R.; BI, S.; JIN, H.; CUI, X.; SHI, F. AND HU, S.2018. Soybean oil containing ginseng saponins as adjuvants promotes production of cytokines and enhances immune responses to foot-and-mouth disease vaccine. Microbiol. Immunol., 62, 187-194.

How to cite this article:

Elsayed E. I., Mossad W.G , Ismail A.H. and Walaa Shabana. 2020. Immuno-Potentiator Effect Of Rapeseed Or Soybean Oil With Foot And Mouth Disease Vaccine In Calves. Journal of Applied Veterinary Sciences, 5(3): 92 - 102.

DOI: HTTPS://DX.DOI.ORG/10.21608/JAVS.2020.103394 